The Journal of Society \& Media 2017, Vol. 1(1) 35 - 42

https://journal.unesa.ac.id/index.php/jsm/index

\title{
KRITIK BUDAYA AKADEMIK DI PENDIDIKAN TINGGI
}

\author{
M. Agus Nuryatno \\ Fakultas Tarbiyah dan Keguruan UIN Sunan Kalijaga Yogyakarta \\ Email: agusnuryanto@ uinkalijaga.ac.id
}

\begin{abstract}
Abstrak
Pendidikan menjadi arena politis dan tidak netral. Karena dari rahim pendidikan akan lahir manusia-manusia idealis atau pragmatis, humanis atau dehumanis, toleran atau intoleran, berintegritas atau krisis integritas, individualis atau sosialis. Pendidikan memiliki peran yang sangat signifikan dalam melahirkan dan membentuk pribadi-pribadi tertentu. Semuanya tergantung pada dasar filosofi dan nilai di atas mana institusi pendidikan dibangun serta praksis pendidikan apa yang dikembangkan. Iklim sosial yang dibangun di kampus, merupakan bagian dari kurikulum tersembunyi (hidden curriculum) yang juga berkontribusi dalam membentuk kepribadian sivitas akademika. Saat ini yang tengah terjadi adalah pertarungan kepentingan antar ideologi dalam pendidikan tinggi, yaitu kontestasi antara pendidikan tinggi yang berbasiskan pada nilai-nilai akademik (academic values) yang cenderung etis-utopis dan yang berbasiskan pada nilai-nilai korporasi (corporate values) yang cenderung praktis-pragmatis. Tarik menarik kepentingan ideologi dalam pendidikan sesungguhnya merupakan tarik menarik kepentingan antara idealisme dan pragmatisme. Seharusnya pendidikan tinggi menjadi bagian dari institusi sosial yang ikut mendorong terbentuknya masyarakat etis-demokratis. Ketika pendidikan tinggi kehilangan nalar kritisnya maka ia tidak mampu menjadi pencerah bagi masyarakat, atau menjadi agent of social change. Tetapi sebaliknya, pendidikan tinggi semakin jauh dari realitas masyarakat.
\end{abstract}

Kata kunci: kritik, perguruan tinggi, budaya akademik

\section{Abstract}

Education becomes political arena and it is not neutral. Because of education womb will create idealistic or pragmatic people, humanist or dehumanis, tolerant or intolerant, integrity or the critical integrity, and individualist or socialist. Education has a very significant role in the birth and form certain individuals. All of it depends on the basic philosophy and values on which educational institutions are built and what educational praxis developed. A social climate that is built on the campus, is part of the hidden curriculum which also contribute in shaping the personality of academic society. Current phenomenon shows that there is a conflict of interests between ideology in higher education, the contestation between higher education based on academic values (academic values) that tend ethical-utopian and based on the values of the corporation (corporate values) which tends practically. Ideology of interests in education is real conflict of the interests between idealism and pragmatism. Higher education is supposed to be part of the social institutions that contributed to the formation of ethical-democratic society. When higher education loses its critical reason, it was not able to be a lightening for the community, or become agents of social change. But on the contrary, higher education is getting away from the reality in particular society.

Keywords: critic, higher education, academic culture

\section{Pendahuluan}

Kata "kritik" menjadi bagian tak terpisahkan dari dunia pendidikan tinggi. Karena "kritik" menjadi bagian penting dalam pengembangan ilmu pengetahuan dan kelembagaan pendidikan. Tanpa "kritik" mustahil ada dinamisasi dan akselerasi ilmu pengetahuan, tanpa "kritik" sulit bagi institusi pendidikan tinggi untuk berkembang karena tidak ada mekanisme 
check and balances. Bila dilacak dalam sejarah ilmu pengetahuan, ada empat eksponen yang dapat dijadikan rujukan mengenai "kritik", yaitu Sigmund Freud, Immanuel Kant, Hegel, dan Karl Marx (F. Hardi Budiman, 2004), dengan variannya masing-masing, mulai dari yang menekankan aspek psikis (Freud), mode of pure reasoning (Kant), refleksi-diri (Hegel), hingga emansipasi diri dari penindasan dan alienasi (Marx). Pengembangan "kritik" dalam dunia kampus berarti mengembangkan kapasitas berpikir sivitas akademika. Jika "kritik" sudah membudaya dalam kehidupan kampus maka kemungkinan menjadikan pendidikan tinggi sebagai media pembentukan masyarakat kampus yang kritis, inovatif, dan dinamis, sebagaimana yang diamanatkan UU PT No. 12 Tahun 2012 Pasal 4 Poin b, dapat terwujud. Tapi jika yang dikembangkan di kampus adalah budaya akademik yang instan, praktis, dan pragmatis maka kampus hanya akan melahirkan culture of silence.

\section{Reafirmasi Ketidaknetralan Pendidikan}

Institusi pendidikan tinggi merupakan bagian dari institusi-institusi sosial lain yang dapat berperan sebagai pendukung hegemoni atau counter hegemoni (Antonio Gramsci, 1971); membangun budaya bisu (culture of silence) atau budaya kritis (culture of critical) (Paulo Freire, 1970); menumbuhkan spirit toleransi atau intoleransi (M. Agus Nuryatno, 2011); memperkuat masyarakat multikulturalisme atau monokulturalisme. Jika demikian halnya, maka pendidikan menjadi instrumen yang politis, bukan a politis. Pendidikan menjadi media yang tidak netral, seperti yang dikatakan Paulo Freire "The neutrality of education is one of the fundamental connotations of the naïve vision of education" (Paulo Freire, 1987: 41). Dalam bahasa lain, pendidikan sesungguhnya sarat dengan muata-muatan dan implikasi-implikasi politis. Joe Kincheloe, salah satu pendukung mazhab pendidikan kritis, mengatakan "Every dimension of schooling and every form of educational practice are politically contested spaces" (2005: 2). Semua aspek dan dimensi dalam pendidikan merupakan ruang-ruang kontestasi.

Mengapa pendidikan menjadi arena politis dan tidak netral? Karena dari rahim pendidikanlah akan lahir manusia-manusia idealis atau pragmatis, humanis atau dehumanis, toleran atau intoleran, berintegritas atau krisis integritas, individualis atau sosialis. Pendidikan memiliki peran yang sangat signifikan dalam melahirkan dan membentuk pribadi-pribadi tertentu. Semuanya tergantung pada dasar filosofi dan nilai di atas mana institusi pendidikan dibangun serta praksis pendidikan apa yang dikembangkan. Iklim sosial yang dibangun di kampus, misalnya, merupakan bagian dari kurikulum tersembunyi (hidden curriculuum) yang juga berkontribusi dalam membentuk kepribadian sivitas akademika. 


\section{Dalam Pusaran Pragmatisme}

Saat ini tengah terjadi pertarungan kepentingan antar ideologi dalam pendidikan tinggi, dan ini merupakan contoh kongkret bagaimana pendidikan itu tidak netral atau politis. Kontestasi yang dimaksud adalah antara pendidikan tinggi yang berbasiskan pada nilai-nilai akademik (academic values) dan yang berbasiskan pada nilai-nilai korporasi (corporate values). Nilai akademik adalah nilai etis-utopis, sedangkan nilai korporasi adalah nilai praktispragmatis. Tarik menarik kepentingan ideologi dalam pendidikan sesungguhnya merupakan tarik menarik kepentingan antara idealisme dan pragmatisme. Di satu sisi, pendidikan punya peran dalam membentuk kehidupan publik, dan bahkan pernyataan yang lebih tepat tidak sekedar memberi afirmasi atas peran pendidikan dalam kehidupan publik, tapi justeru pertanyaan "Kehidupan publik seperti apa yang hendak dibentuk oleh dunia pendidikan?" (Neil Postman, 1995). Pendidikan diyakini memainkan peranan yang signifikan dalam membentuk kehidupan politik dan kultural. Pendidikan adalah media untuk menyiapkan dan melegitimasi bentuk-bentuk tertentu kehidupan sosial. Jika hal seperti ini yang dikedepankan, maka yang menjadi basis institusi pendidikan adalah nilai-nilai idealisme (academic values).

Jika pertanyaan di atas dibalik menjadi "Pendidikan seperti apa yang hendak dibentuk oleh pasar?" maka dunia pendidikan akan terseret dan didekte oleh kepentingan pasar. Ideologi pasar jelas berbeda dengan ideologi pendidikan. Ideologi pendidikan lebih mementingkan nilai-nilai etis-humanistik, sedangkan ideologi pasar lebih bertumpu pada nilai-nilai pragmatismaterialistik dan menekankan kompetisi dibanding koperasi. Ketika ideologi pasar yang dominan maka pendidikan telah direduksi maknanya sebatas penguasaan teknik-teknik dasar yang diperlukan dalam dunia kerja (M. Agus Nuryatno, 2008). Institusi pendidikan yang berbasis pada nilai-nilai korporasi atau pasar akan melahirkan sivitas akademika yang mode of thought-nya adalah rasionalitas teknokratik (technocratic rationality) yang punya dua karakter utama: konformitas dan uniformitas. Konformitas berarti sivitas akademika diarahkan untuk bersikap adaptif dan pasif terhadap perubahan yang ada, tanpa perlu terlibat dalam proses penciptaan sejarah, atau menjadi subyek sejarah. Uniformitas berarti masyarakat kampus diarahkan untuk berpikir tunggal dan seragam dalam melihat persoalan, tidak keluar dari kotak habitus sendiri. Rasionalitas teknokratik memiliki kontribusi dalam mendegradasi kesadaran historis-kritis sivitas akademika dengan cara menggeser ide tentang perkembangan diri mereka yang bersifat moral dan etis dengan hanya menekankan pada perkembangan diri yang bersifat teknis-material (Henry A Giroux, 1993). 
Rasionalitas teknokratik hanya menekankan pada kepentingan-kepentingan pragmatis, atau apa yang disebut dengan what is, tapi tidak memberi perhatian terhadap kepentingankepentingan yang bersifat idealis-utopis, atau apa yang disebut dengan what should dan can be. Akibatnya, nilai-nilai korporasi yang lebih pragmatis-teknis dikedepankan sementara nilainilai moral-etis terpinggirkan. Tidak mengherankan jika saat ini banyak sivitas akademika lebih suka membuat karya ilmiah tidak berbasis pada buku, tapi berbasis internet yang lebih mudah, instan, dan tidak perlu bersusah payah. Banyak mahasiswa lebih suka membaca bukubuku "how to" yang ringan dan mudah dibaca tapi tidak mempertajam akal-budi daripada buku-buku filsafat yang kaya pengetahuan, inspiratif, dan mempertajam akal-budi dan nurani. Mahasiswa lebih banyak memilih Prodi-Prodi yang menjanjikan peluang kerja di masa depan daripada Prodi-Prodi yang berbau pemikiran. Walhasil, saat ini pendidikan tinggi telah direduksi maknanya sebatas investasi ekonomi untuk mendapat lapangan pekerjaan, tidak lagi dimaknai secara lebih substantif, yaitu menyiapkan manusia untuk hidup di dan bersama dunia (Paulo Freire, 1987). Pendidikan sesungguhnya merupakan media untuk menyiapkan manusia memiliki otonomi, kemandirian, dan kemampuan untuk tidak sekedar hidup di dunia tapi juga terlibat dalam proses transformasi dunia. Inilah kehidupan yang otentik, sebagaimana yang dikatakan oleh Colin Lankshear (1993:95), “humans are 'beings of the praxis' who live authentically only when engaged in inquiry and creative transformation of the world."

Di tengah pusaran pragmatisme, dunia pendidikan tinggi menjadi miskin kritik akademik atas realitas sosial. Dalam arus ini, dunia pendidikan tinggi telah kehilangan, meminjam bahasa Henry A Giroux (1987), "language of critique" dan "language of possibility"-nya, yaitu kehilangan ketajaman nalar kritiknya atas dunia publik yang tidak sesuai dengan idealisme akademik, dan pada saat yang sama tidak mampu menawarkan kemungkinan-kemungkinan dikembangkannya wilayah-wilayah publik yang demokratis (democratic public spheres). Ini merupakan alarm bagi eksistensi pendidikan tinggi, yang seharusnya, menjadi bagian dari institusi sosial yang ikut mendorong terbentuknya masyarakat etis-demokratis. Ketika pendidikan tinggi kehilangan nalar kritisnya maka ia tidak mampu menjadi pencerah bagi masyarakat, atau menjadi agent of social change. Dan, justeru sebaliknya, pendidikan tinggi semakin jauh dari realitas masyarakat.

\section{Pendidikan Anti-Realitas}

Saat ini dunia pendidikan nasional dihadapkan pada fenomena yang disebut oleh Musa Asy'arie (2005) dengan "pendidikan sekolah anti realitas." Apa yang dimaksud dengan pendidikan anti realitas adalah pendidikan yang tidak berbasis pada kebutuhan dan realitas 
kehidupan masyarakat luas. Misalnya, sebagian besar masyarakat Indonesia adalah masyarakat agraris yang berbasiskan pada pertanian dan perkebunan. Namun ironinya, Indonesia belum mampu mengembangkan budaya pertanian dan perkebunan yang baik dan produktif melalui pendidikan. Akibatnya, Indonesia belum mampu memenuhi kebutuhan dalam negeri sendiri, dan untuk menutupinya harus impor dari luar seperti beras, buah-buahan, kedelai, dan bahkan garam. Karena tidak adanya political will dari pemerintah untuk mengembangkan pertanian dan perkebunan maka profesi petani menjadi profesi pinggiran yang sama sekali tidak dïmpikan oleh mayoritas mayarakat Indonesia. Hampir tidak ada anak Indonesia saat ini yang bercita-cita menjadi petani, padahal mayoritas warganya hidup dalam wilayah agraris. Fakultas pertanian-pun menjadi fakultas yang sepi peminat. Ini menunjukkan adanya gap antara pendidikan dan realitas.

Pendidikan yang anti realitas tidak berpijak di bumi. Teori-teori yang diajarkan di persekolahan dan perguruan tinggi tidak mencerminkan apa yang terjadi dalam kehidupan peserta didik. Sebabnya teori-teori yang diajarkan adalah teori-teori yang dikonstruksi di ruang dan tempat yang berbeda; teori-teori ini berasal dari belahan bumi yang lain. Jika tidak dilakukan kontekstualisasi, maka teori-teori tersebut menjadi kurang bermakna bagi kehidupan peserta didik. Apalagi teori tidaklah netral, atau free-value, tapi selalu didasarkan pada satu nilai atau ideologi tertentu (Jurgen Habermas, 1984; M. Agus Nuryatno, 2007). Tragisnya, apapun teori yang diajarkan dalam pendidikan kita adalah teori a-historis, tidak berbasis pada konteks lokal. Sehingga relevansi dan signifikansinya terhadap kehidupan peserta didik patut dipertanyakan.

Kecenderungan dominan penelitian-penelitian akademik yang dilakukan dalam dunia pendidikan tinggi lebih mengarah pada penggunaan teori Barat untuk memahami konteks lokal kita, tapi jarang sekali ada penelitian yang menjadikan konteks lokal sebagai basis untuk mengonstruksi teori, seperti yang disarankan oleh Linda Tuhiwai Smith (1999). Akibatnya, dunia pendidikan tinggi miskin sekali melahirkan teori-teori baru yang berbasis pada konteks lokal, dan pada gilirannya, dunia pendidikan tinggi lebih berperan sebagai konsumen daripada produsen ilmu. Meskipun dalam metodologi penelitian selalu disebutkan bahwa penelitian kualitatif berorientasi untuk menemukan teori-teori baru, tapi pada kenyataannya tidak seperti yang dideskripsikan. Jarang sekali penelitian-penelitian akademik, apakah itu skripsi, tesis, maupun disertasi, yang berakhir dengan penemuan teori-teori baru.

Saat ini memang ada kecenderungan pendidikan tinggi di Indonesia lebih menjadikan mahasiswsa sebagai konsumen ilmu, teori, atau konsep, daripada produsen. Mereka tidak diajak untuk merefleksi bagaimana seorang pakar di bidang tertentu menemukan atau 
melahirkan sebuah teori, atau diajak untuk mengkritisi atau mendemitologisasi ideologi di balik teori, padahal di balik teori selalu ada nilai dan ideologi (Fransisco Hardi Budiman, 2004). Ini menandakan bahwa proses pendidikan dan pengajaran di pendidikan tinggi baru sebatas pada tahap penerimaan teori, konsep, dan pengetahuan, yang lebih menekankan aspek pemahaman. Dalam konsep hirarki konstruksi pengetahuan, ini adalah tahap yang paling dasar. Tahap kedua di atasnya adalah tahap critical reflection of theory, yaitu tahap kritisisme, bagaimana menyingkap bias-bias ideologi di balik teori. Tahap ketiga adalah contextualization of theory, yaitu bagaimana melakukan kontekstualisasi teori ke dalam konteks lokal, sejauh mana teori yang dikonstruksi pada ruang dan waktu yang berbeda dapat diterapkan dalam ruang sosial kita. Tahap yang paling tinggi adalah theoritical production, bagaimana memproduksi teori berbasiskan pada konteks lokal. Jika keempat tahapan ini sudah menjadi tradisi dalam dunia pendidikan tinggi maka dunia pendidikan kita tidak semata-mata menjadi consumer of theory, tetapi juga producer of theory. Sayangnya, hingga level penulisan disertasi-pun masih banyak yang belum mampu menjawab tantangan ini: melahirkan teori baru berbasis penelitian pada konteks lokal.

Selain miskin dalam melahirkan teori, pertanyaan lain yang perlu diajukan adalah sejauhmana signifikansi pendidikan tinggi terhadap realitas sosial? Pertanyaan ini penting untuk diungkap karena konstribusi pendidikan tinggi terhadap perubahan sosial memang perlu dipertanyakan. Sudah ribuan skripsi, tesis, dan disertasi dilahirkan perguruan tinggi, tapi sejauhmana signifikansi penelitian-penelitian akademik tersebut dengan perubahan sosial. Kenyataan menunjukkan bahwa karya-karya akademik ilmiah tersebut memiliki dampak yang tidak begitu signifikan terhadap perubahan sosial. Mengapa? Kemungkinan paradigma penelitian yang digunakan lebih banyak didominasi oleh paradigma penelitian positivistik dan hermenuitik. Tujuan penelitian positivistik adalah memahami tingkah laku manusia berbasiskan pada prinsip-prinsip ilmu alam. Sedangkan tujuan penelitian hermenuitik adalah memahami dan menafsirkan tingkah laku manusia melalui penafsiran terhadap pengalaman hidup mereka. Kedua pendekatan penelitian ini tidak sampai pada tahap transformasi, yaitu menjadikan pemahaman dan penafsiran terhadap tingkah laku manusia sebagai basis untuk melakukan upaya-upaya perubahan sosial masyarakat yang diteliti, seperti yang menjadi prinsip dalam penelitian berbasis teori kritis (critical theory) (J. Amos Hatch, 2002). Kenyataan menunjukkan bahwa masih sangat minim seklai penelitian akademik di perguruan tinggi yang berrbasis pada teori kritis, atau dengan menggunakan model Participatory Action Research (PAR). Inilah mungkin salah satu yang menyebabkan kenapa penelitian akademik di kampus kurang memiliki dampak sosial. 


\section{Back to Pancasila}

Oleh karena itu, perlu mengembalikan nalar kritik kampus pendidikan tinggi dengan cara keluar dari lingkaran kekuasaan dominasi pragmatisme, dan kembali ke dasar falsafah pendidikan nasional, yaitu Pancasila, yang di dalamnya terdapat muatan spiritualitas, humanisme, kesatuan dalam keragaman, demokrasi, dan keadilan. Jika nilai-nilai ini menjadi fondasi dasar pendidikan tinggi, maka peluang untuk mempertahankan nalar kritis-nya menjadi terjaga. Pancasila memang secara normatif menjadi basis falsafah dalam kehidupan berbangsa dan bernegara, dan pendidikan nasionalpun juga didasarkan pada falsafah ini. Namun pada tingkatan praksis, yang dominan justeru bukan falsafah Pancasilanya tapi ideologi lain yang berbasis pada kapitalisme-neoliberalisme yang bertumpu pada ideologi kompetisi dan nilainilai korporasi.

\section{Penutup}

Tugas pendidikan tinggi adalah memberikan pencerahan terhadap sivitas akademika dan masyarakat luas. Eksistensi perguruan tinggi tidak boleh di menara gading yang tidak terjamah oleh masyarakat luas. School is a mirror of society. Ketika pendidikan tinggi jauh dari masyarakat maka pendidikan tinggi menjadi anti-realitas, tercerabut dari akar sosial peserta didik. Pendidikan anti-realitas merupakan dampak sistematis dari dominasinya ideologi pragmatisme dalam pendidikan. Dalam pusaran pragmatisme, sivitas akademika digiring untuk berpikir praktis, instan, dan pragmatis. Mereka semakin dijauhkan dari pemikiran-pemikiran falsafati yang mengasah akal-budi dan membuat kritis terhadap teks dan konteks. Di sinilah perlu untuk mengembalikan budaya akademik kampus yang berbasis pada rasionalitas teknokratik menuju pada rasionalitas kritis.

\section{Referensi}

Asy'arie, Musa, "Pendidikan Sekolah Kita Anti Realitas", dalam buku NKRI, Budaya Politik dan Pendidikan. Yogyakarta: LESFI, 2005.

Budiman, Fransisco Hardi. Kritik Ideologi: Menyingkap Kepentingan Dibalik Pengetahuan Bersama Jurgen Habermas, Yogyakarta: Buku Baik, 2004.

Freire, Paulo. Pedagogy of the Oppressed, New York: Herder and Herder, 1970.

Freire, Paulo dan Donaldo P. Macedo. Literacy: Reading the Word and the World. South Hadley, Mass.: Bergin \& Garvey Publishers, 1987. 
Giroux, Henry A. Border Crossing: A Cultural Workers and the Politics of Education. New York: Routledge, 1993.

Gramsci, Antonio. Selections from the Prison Notebooks, New York: International Publishers, 1971.

Habermas, Jurgen. Knowledge and Human Interest; Boston: Beacon, 1971

Hatch, J. Amos. Doing Qualitative Research in Education Setting. Albany: State University of New York Press, 2002.

Kincheloe, Joe L. Critical Pedagogy. New York: Peter Lang, 2005

Lankshear, Colin. Functional Literacy from a Point of View. Dalam Peter McLaren dan Peter Leonard (Ed.), Paulo Freire: A Critical Encounter. London dan New York: Routledge, 1993.

Nuryatno, M. Agus. The Call for the Paradigm Shift in Research Methodology, Jurnal Studi Islam Mukaddimah, No. 22 Th VIII/2007.

Nuryatno, M. Agus. Mazhab Pendidikan Kritis. Yogyakarta: Resist Book, 2008

Nuryatno, M. Agus. (2011). "Islamic Education in a Pluralistic Society," dalam Al-Jamiah, No. 2, Vol. 2, 2011

Postman, Neil. The End of Education: Redefining the Value of School. New York: Alfred A. Knopf, 1995

Smith, Linda Tuhiwai. Decolonizing Methodologies, London: Zed Books, 1999.

Undang-Undang Pendidikan Tinggi No. 12 Tahun 2012 